\title{
Spatial distribution of human and canine visceral leishmaniasis in Belo Horizonte, Minas Gerais State, Brasil, 1994-1997
}

Cláudia Di Lorenzo Oliveira 1,2

\author{
Distribuição espacial da leishmaniose visceral \\ humana e canina em Belo Horizonte, Minas Gerais, \\ Brasil, 1994-1997
}

Renato Martins Assunção 3

Ilka Afonso Reis 3

Fernando Augusto Proietti 4

\footnotetext{
${ }^{1}$ Hospital das Clínicas, Universidade Federal de Minas Gerais. Rua Alfredo Balena 110, Campus Saúde, Belo Horizonte, $M G$ 30130-100, Brasil. dlorenzo@medicina.ufmg.br 2 Fundação Nacional de Saúde. Av. Espírito Santo 500, Belo Horizonte, $M G$ 30160-030, Brasil.

3 Departamento de Estatística, Universidade Federal de Minas Gerais. C. P. 702, Belo Horizonte, $M G$ 30161-970, Brasil.

4 Departamento de Medicina Preventiva e Social, Universidade Federal de Minas Gerais. Av. Alfredo Balena 190, 9 a andar, Belo Horizonte, $M G$ 30130-100, Brasil.
}

\begin{abstract}
In this paper, we present spatial analysis of the association between all incidents cases of human Visceral Leishmaniasis and seropositive dogs, from 1994 to 1997 in Belo Horizonte, a large Brazilian city. We geocoded 158 human cases and 11,048 seropositive dogs and compared canine prevalence rates with Human Bayesian Incidence rates in the same areas. We also used Knox's test to evaluate the hypothesis of space-time clustering of human cases in the period. Additionally, we used Kernel's maps for seropositive dogs distribution and located the human cases in the resulting smooth maps. We concluded that human and dog rates are correlated. Also, the Visceral Leishmaniasis in Belo Horizonte spread quickly, but apart from the rates' magnitude, it has kept the same spatial pattern through time. We believe it is possible to use this technique to choose areas to implement control measures against Visceral Leishmaniasis in a more efficient way.
\end{abstract}

Key words Spatial Analysis; Spatial Distribution; Visceral Leishmaniasis

Resumo Neste artigo, apresentamos uma análise espacial da associação entre todos os casos incidentes de leishmaniose visceral e em cães soropositivos ocorridos em Belo Horizonte no período de 1994 a 1997. Geocodificamos 158 casos humanos e 11.048 cães positivos, comparamos as taxas de prevalência canina por área e as taxas Bayesianas de incidência da doença humana nas mesmas áreas. Usamos o teste de Knox para testar a hipótese de cluster espaço temporal entre os casos humanos no período examinado. Adicionalmente, construímos Mapas de Kernel para cães soropositivos e sobrepusemos os casos humanos em quatro áreas. Os resultados apontam para correlação entre casos humanos e caninos. Além disso, a leishmaniose visceral espalhou-se rapidamente em Belo Horizonte, embora tenha mantido o mesmo padrão durante os anos analisados. Acreditamos ser possível o uso das técnicas empregadas para priorizar áreas onde as medidas de controle devem ser implementadas.

Palavras-chave Análise Espacial; Distribuição Espacial; Leishmaniose Visceral 


\section{Introduction}

Visceral Leishmaniasis (VL) is an anthropozoonosis with worldwide distribution. The World Health Organization (WHO) estimates that there are five thousand new human cases per year in the world (WHO, 1998). In 1997, 2,572 cases were notified in Brazil and $87 \%$ occurred in the Northeast. In our country, VL is caused by Leishmania chagasi, the vector is Lutzomya longipalpis, and dogs and foxes are the most important domestic and wild reservoir, respectively. The Brazilian Ministry of Health recommended three control measures: early treatment of sick people, spray insecticides in the houses and seropositive dogs euthanasys (FNS, 1996).

In Belo Horizonte, a large Brazilian city, only one human case was confirmed until 1993 (Resende \& Bastos, 1959). In 1994, 35 human cases were reported, followed by 44 cases in 1995, 51 cases in 1996, and 39 cases in 1997. During these years, more than 1.5 million dollars were spent with VL control in the city. Some cases $(n=19)$ occurred in a State sponsored Institution for abandoned children called Fundação Estadual do Bem Estar do Menor (FEBEM). In a specific family, referred to as the G Family in this paper, eight cases occurred. Visceral Leishmaniasis is a focal disease and the clustering of new cases in the same dwelling is not a rare event in Brazil.

Visceral Leishmaniasis is a reemerging disease because it is expanding very quickly to new areas (Morse, 1995). Besides that, Wijeyaratne et al. (1994) wrote that as compared to other parasitological diseases, VL has a higher risk with urbanization, because migration is an important determinant for urban visceral leishmaniasis. In general, the immigrants are low income people who live in poor conditions. Other problems like occupation, sex, age and environmental changes contribute to increase VL in large cities like Belo Horizonte.

The objective of this paper is to study the spatial association between VL in dogs and people, the space-time correlation of human cases from 1994 to 1997, and to suggest specific smallers areas to focus intervention on with insecticides.

\section{Material}

From 1994 to 1997, 169 human cases were confirmed and classified by the symptoms onset. They were identified from the notified cases database maintained by the Epidemiologic Ser- vice (ES) and Zoonosis Service (ZS) from the Belo Horizonte Health Departament. We were able to geocode $93.5 \%$ of the human cases corresponding to 158 cases.

We also included data from 13,746 seropositive dogs stratified by blood collection from the year's ZS database. ZS collected canine blood from many different areas since 1993, either by bleeding all dog populations there or by cluster sampling. In 1995, ZS field work covered practically the whole city, $50 \%$ through household census, the other $50 \%$ by systematic sampling with the rate varying from 1 in 2 to 1 in 20 households. Due to increasing costs, starting in 1996, ZS did not cover areas with prevalence rate below $1 \%$ in the previous year. The other areas were covered by census or high rate systematic sampling. Details can be found in Oliveira (1999). From the database, we were able to geocode 11,048 (80.3\%) seropositive dogs.

Belo Horizonte is a large city, located at 858 meters above sea level, the average annual temperature is $20.5^{\circ} \mathrm{C}$. The climate is tropical and the rainfall is $1450 \mathrm{~mm} /$ year. The last National Census in 2000 counted 2,229,697 million people, and about 560,938 houses. The city has $6,607,600 \mathrm{~m}^{2}$ of preserved green areas. However, there is an estimated deficit of $34,795,604 \mathrm{~m}^{2}$ for the year 2010. The expansion of the city could be separated in three periods. The first period starts around 1908, when the city was built. The space of the city was shared according to social status. The second period starts after the 50's and represents the industrialization of the city. In the 60's, the shanties were built in the city and have been continuously expanding since then. In the second half of the 70's, the city expanded very quickly and between 1970 and 1980 the Belo Horizonte Metropoli$\tan$ Area grew $32.9 \%$. The last period is the verticalization of the city. The single houses in the downtown area were almost completely replaced by tall buildings.

The Public Health Service is organized into 126 districts called Áreas de Abrangência (AA). For each AA, we calculated the human incidence rate and the percentage of seropositive dogs. Due to extreme variability caused by small numbers of cases in each AA, the human incidence rate was corrected using a spatial Bayesian approach introduced by Assunção et al. (in press). The Bayesian estimates highlights the underlying spatial patterns of the rates by eliminating much of the randomness not associated with risk factors. 


\section{Methods}

We used two kinds of spatial data: area data and point pattern and four different statistical techniques:

Linear regression to model the relationship between human incidence rates in an area and the dogs' prevalence rates in the same area in the previous period (see below).

A statistical test (Knox's test) for the hypothesis of space-time interaction using only the human cases.

A statistical test for spatial clustering of human cases confirmed from 1994 to 1997 and the same statistical test to evaluate spatial clustering of seropositive dogs in four selected AA during 1995.

Smooth Kernel estimate of a dogs' prevalence map in the same four selected AA in 1995 and spatial location of all human cases in the same areas.

A more detailed description of the statistical techniques follow:

The first statistical method is based on linear regression models to study the relationship between the Bayesian incidence rates in a given AA and specific year, along with the dogs' prevalence rates in a previous period (six months). In this report we describe in detail why, based on the current knowledge about the disease trasmission dynamics, we adopted a time lag for the latter variable.

The linear regression model for a given year is: $\mathrm{Y}_{i}=\alpha+\beta \mathrm{X}_{i-1}+\mathrm{e}_{i}$

where $Y_{i}$ is the vector of the logarithm of Bayesian Incidence Rates of the AA's in year $i$ for human, and $X_{i-1}$ is the vector of the logarithm of dogs prevalence rates of the AA's during the previous period. The year index represents one of the following calendar periods: August, 1995 to July,1996; August, 1996 to July, 1997 and August, 1997 to July, 1998. The corresponding previous periods are: January to December, 1995; January to December, 1996; January to December, 1997.

The disease incubation period for humans varies between 3 and 6 months, although it can reach 12 months, occasionally. Hence, the observed human incidence in a year $i$ is associated to the infection acquired at a previous time. We used the canine prevalence rates during the previous period as an index of the canine prevalence rates at the infection moment for the human cases.

In summary, we allowed for a delay of six months for the impact of the dogs' prevalence in human rates. The logarithm was taken because of the large assimetry and unequal vari- ability of the rates. Although we cannot find any visual or statistical significant relationship in the original rate scale, there is a graphically clear linear pattern when the logarithm is used (graph not shown).

We ran three regression models and each of them used data from all areas excluding AA's with canine prevalence rates equal to zero. We had 78 AAs in the first period, 67 in the second period and 60 in the third period. For this analysis, we used the software Stata 6.0 (Stata Corporation, 1999).

To study space-time interaction, we used the Knox test which is based on the number of pairs of events in a short distance in both, space and time (Knox, 1964). We classified each pair of human events according to their proximity in space (less than $500 \mathrm{~m}$ ) and time (less than 3 months). Then, we compared the observed number of pairs which are simultaneously close in time and space with what is expected under the assumption of independence of space and time. If the null hypothesis of no interaction is rejected, we accept the alternative hypothesis that the spatial pattern of the rates is changing in time. The correct test distribution was found by Mantel (1967). The 155 human cases were classified by the month the symptoms appeared. If this date was unknown, we used the date of the first medical appointment. Three cases without known dates were excluded from the analysis.

Concerned with the possibility that statistical significance of space-time interaction can be caused mainly because of multiple events in same address, we made three different analyses. In the first one, we considered all cases. In the second analysis, we excluded the 19 FEBEM cases and $8 \mathrm{G}$ family cases. In addition to FEBEM and $\mathrm{G}$ family cases exclusion, the third analysis also eliminated all pairs of cases living at the same address. Note that we excluded the pairs, but not the individuals composing the pairs. That is, if two individuals live in the same address, we do not consider the pair formed by them, but we did consider all pairs formed by one of them, and any other event from another address.

This analysis required an adaptation of the Knox test since it is being applied to all pairs of cases conditioned by their distance being greater than zero. The test statistic distribution under the null hypothesis is not the one found by Mantel and we developed a special computer code to carry out a conditioned permutation test. We had 8,640 pairs of events which had distance greater than zero. For each pair $(i, j)$, we calculated two values: its distance $s i j>0$ 
and its time difference $t_{i j}$. These values were organized in a 8,640 x 2 table. If there is no spacetime interaction then all tables with the second column permuted have the same probability. The test statistic distribution is based on this permutation distribution. The code is available from the second author upon request.

The $\mathrm{K}$ function was constructed to detect spatial clustering of events located as points in a map for both, human cases and seropositive dogs (Ripley, 1977). For the human cases, we compared the K function obtained with all cases and those obtained with only one case in each address. The difference between the $\mathrm{K}$ functions of these two groups did not show statistically significant difference and therefore we analysed only those based on all cases. This analysis was conducted using the S-Plus software (Mathsoft Incorportion, 1997).

For the K-function analysis of seropositive dogs, we chose four AA, and the year 1995 because they presented a large number of human cases and all dogs was geocoded. We used MapInfo 3.1 (MapInfo Coporation, 1994) to geocode dogs and human cases, and the InfoMap software (Infomap, 1995) for the spatial analysis. Using these same four AA, and the year 1995, we made Kernel maps of the density of the dog's events. In each location $s$ of a fine regular grid superimposed on, the methods estimates the average number of events per unit area. These estimates are obtained as a type of weight count of events per unit area where the weight decrease with the distance between the location $s$ and the event being counted. The weight decrease rate is determined by a parameter called bandwidth which was chosen by trial and error in our study. Occasionally, there is enough epidemiological knowledge to choose the bandwidth (Souza-Santos \& Carvalho, 2000). More specifically, the density of events at location $s$ is given by

$$
\hat{\lambda}(s)=\sum_{i=1}^{n} \frac{1}{\tau^{2}} K\left(\frac{\left(s-s_{i}\right)}{\tau}\right)
$$

Where $t$ is the bandwidth parameter, $s$ is the location of interest, $s i$ is the location of $i-t h$ event and $K()$ is the Kernel function representing the weights. We used a quartic bivariate probability density function as the Kernel. We plotted the human cases on top of the kernel maps.

\section{Results}

From 1994 to 1997, 169 human cases of VL were confirmed and 158 (93,6\%) were geocoded. Five cases were homeless individuals, and hence they were excluded from the analysis. Furthermore, six other individuals could not be located since their reported addresses were not in the database. Concerning the dogs, $80,3 \%$ were geocoded by their owners' addresses while $11,1 \%$ were missing. For $8,6 \%$ the reported addresses could not be found in the database. The geocoding missing rate was nearly constant during the years 1995, 1996 and 1997, the years used in the linear regressions (Table 1).

Table 2 shows the linear regression fit results using the logarithm scale for both the dependent and independent variables. The $\mathrm{p}$-value is smaller than 0.005 in all periods studied and therefore shows is a highly significant linear correlation between the human incidence rate and the prevalence rate in dogs in the previous period. Areas where the prevalence rate in dogs was high also had high human incidence rate. If we denote by $h$ the human rate and by $c$ the canine rate, we can revert the regression results from the logarithm scale to the original scale obtaining, approximately:

- for 1995/1996, $h=\exp (-0.652) c^{1.397}$

- for $1996 / 1997, h=\exp (-12.520) c^{1.219}$

- for 1997/1998, $h=\exp (-12.170) c^{1.016}$

Hence, the human rates are roughly proportional to canine prevalence rates.

Table 3 presents the results of the Knox test for the space-time interaction hypothesis. Considering all available cases, the $\mathrm{p}$ value is 0.00002 , a highly significant result. However, when we excluded FEBEM and G Family cases, the $p$ value increases to 0.043 , a slightly significant result at the usual 0.05 level. If we carry out the test conditioning on the set of pairs living in different addresses, the $\mathrm{p}$ value increases further to 0.11 , lacking significance at the usual levels. Therefore, the statistical significance of space-time interaction depends strongly on allowing same the address pairs to be considered.

Figure 1 shows the $\mathrm{K}$ function for all human cases notified in Belo Horizonte compared with $\mathrm{K}$ function for just one case in the same address. Figure 2 shows the estimated K function to test for dogs' cases clustering with its 95\% confidence envelope (as dashed lines) for four areas. Since the estimated K function does not lie between the envelope curves, there is evidence of spatial clustering of the cases inside each of the areas. Figure 3 shows the kernel map to estimate the density of positive dogs with human cases superimposed. The dark gray means the highest density of seropositive dogs. We note that the human cases occurred in regions where the density of positive dogs is relatively high. 


\section{Discuss and conclusion}

The 1970's was an important period of expansion for the Belo Horizonte Metropolitan Area. The population increased significantly as many people from smaller cities migrated to suburban areas of Belo Horizonte. This migration is one of the most important factors of the urbanization of parasitologic diseases (Mott et al., 1991). Visceral Leishmaniasis has a relative long assintomatic evolution in dogs. The first human case from the Belo Horizonte Metropolitan Area was confirmed in Sabará city in 1989. Sabara city is a satellite town located to the east of Belo Horizonte city. In 1994, the first human autochthonous case was discovered in the Belo Horizonte Metropolitan Area, it was from the East side of town, near the Sabara city limits. We believe that dogs in that area were susceptible, because they never had contact with the disease. In consequence, the epidemic spread very fast in the City of Belo Horizonte. The number of cases is now expanding and have been confirmed in many areas in and around Belo Horizonte.
Since seropositive dogs and humans live next to each other, it is not surprising that classical studies of VL have stressed the importance of dogs in the natural history of the disease (Alencar et al., 1993; Deane, 1956; Deane \& Deane, 1955, 1962; Deane et al., 1955; Magalhães et al., 1980). One difficulty faced by health official is due to the lack of symptons on infected dogs for as long as two years. During this period, a seropositive dog will be a source of in-

Table 1

Seropositive dogs by survey year. Belo Horizonte, 1993-1994.

\begin{tabular}{lrrrrrr}
\hline Year & Collected & $\%$ & Keyed-in & $\%$ & Geocoded & $\%$ \\
\hline 1993 & 133 & 100.0 & 112 & 84,2 & 78 & 58.7 \\
1994 & 468 & 100.0 & 438 & 93,6 & 418 & 95.4 \\
1995 & 3,870 & 100.0 & 3,415 & 88,2 & 3,415 & 88.2 \\
1996 & 4,754 & 100.0 & 4,002 & 84,2 & 3,524 & 74.1 \\
1997 & 4,521 & 100.0 & 4,265 & 94,3 & 3,613 & 84.7 \\
Total & 13,746 & 100.0 & 12,232 & 88,9 & 11,048 & 80.3
\end{tabular}

Source: Zoonosis Service.

Table 2

Results of linear regression of human visceral leishmaniasis $(Y)$ rates in previous canine prevalence rates $(X)$ by areas. Belo Horizonte, 1995-1998.

\begin{tabular}{lccccc}
\hline Year & $\begin{array}{c}\text { Observed } \\
\text { areas }\end{array}$ & Coefficient $(\beta)$ & $\begin{array}{c}\text { Standard } \\
\text { Error }\end{array}$ & t-Student & $\begin{array}{c}\text { p value } \\
\text { Confidence } \\
\text { Interval }\end{array}$ \\
\hline $\begin{array}{l}X \\
Y\end{array}$ & 78 & 1.397 & 0.204 & 6.823 & 0.000 \\
$Y=1995 / 1996$ & 67 & 1.219 & 0.169 & 7.184 & 0.000 \\
$X=1996$ & & & & & $0.98-1.80$ \\
$Y=1996 / 1997$ & 60 & 1.016 & 0.156 & 6.509 & 0.000 \\
$X=1997$ & & & & & $0.70-1.33$ \\
$Y=1997 / 1998$ & & & & &
\end{tabular}

* A predicted value calculated by Assunção et al. (in press) was used for 1998.

Table 3

Knox test results for all cases, excluding FEBEM and G family cases, and excluding additionally all pairs living at the same address. Belo Horizonte, 1994-1997.

\begin{tabular}{lcccc}
\hline Tested group & Knox test & Expected value & Observed value & $\mathbf{p}$ value \\
\hline All cases & 4.002 & 101.644 & 142 & 0.00002 \\
Excluding FEBEM and G family cases & 1.669 & 60.962 & 74 & 0.043 \\
Excluding same-address pairs & 1.305 & 59.899 & 70 & 0.11 \\
\hline
\end{tabular}

FEBEM = Fundação Estadual do Bem Estar do Menor (State Child Welfare Foundation). 
Figure 1

K function for all human cases $(n=158)$ and only one case per address $(n=128)$. Bands refer to 100 .

Belo Horizonte, 1994-1997.

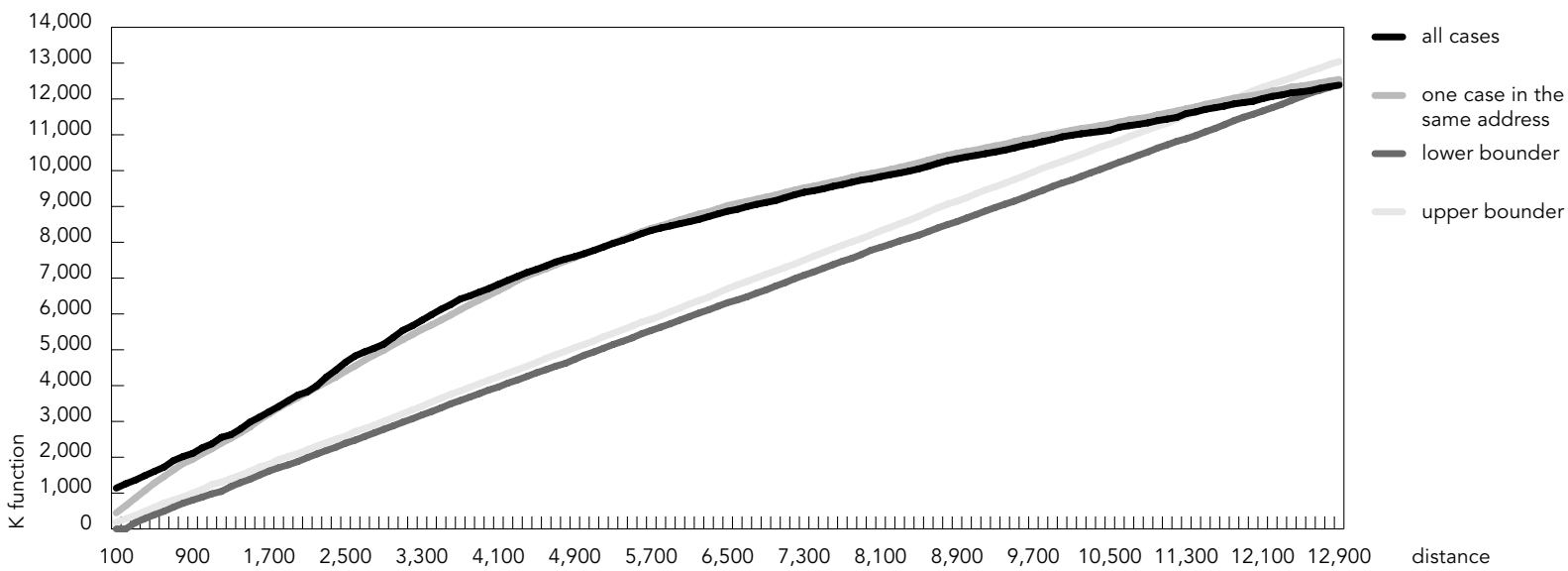

Figure 2

Univariate K function for seropositive dogs from four areas. Belo Horizonte, 1995.
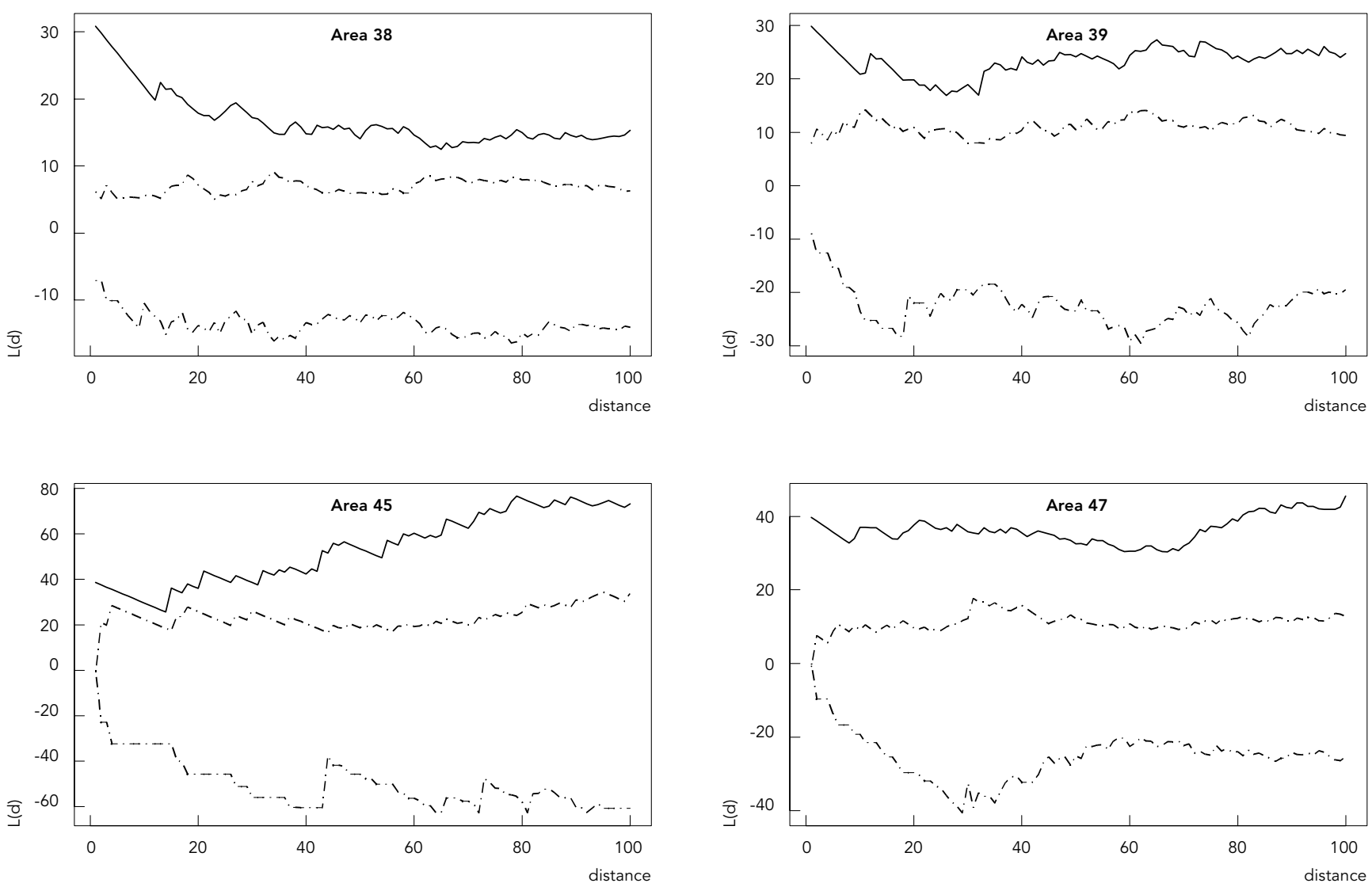

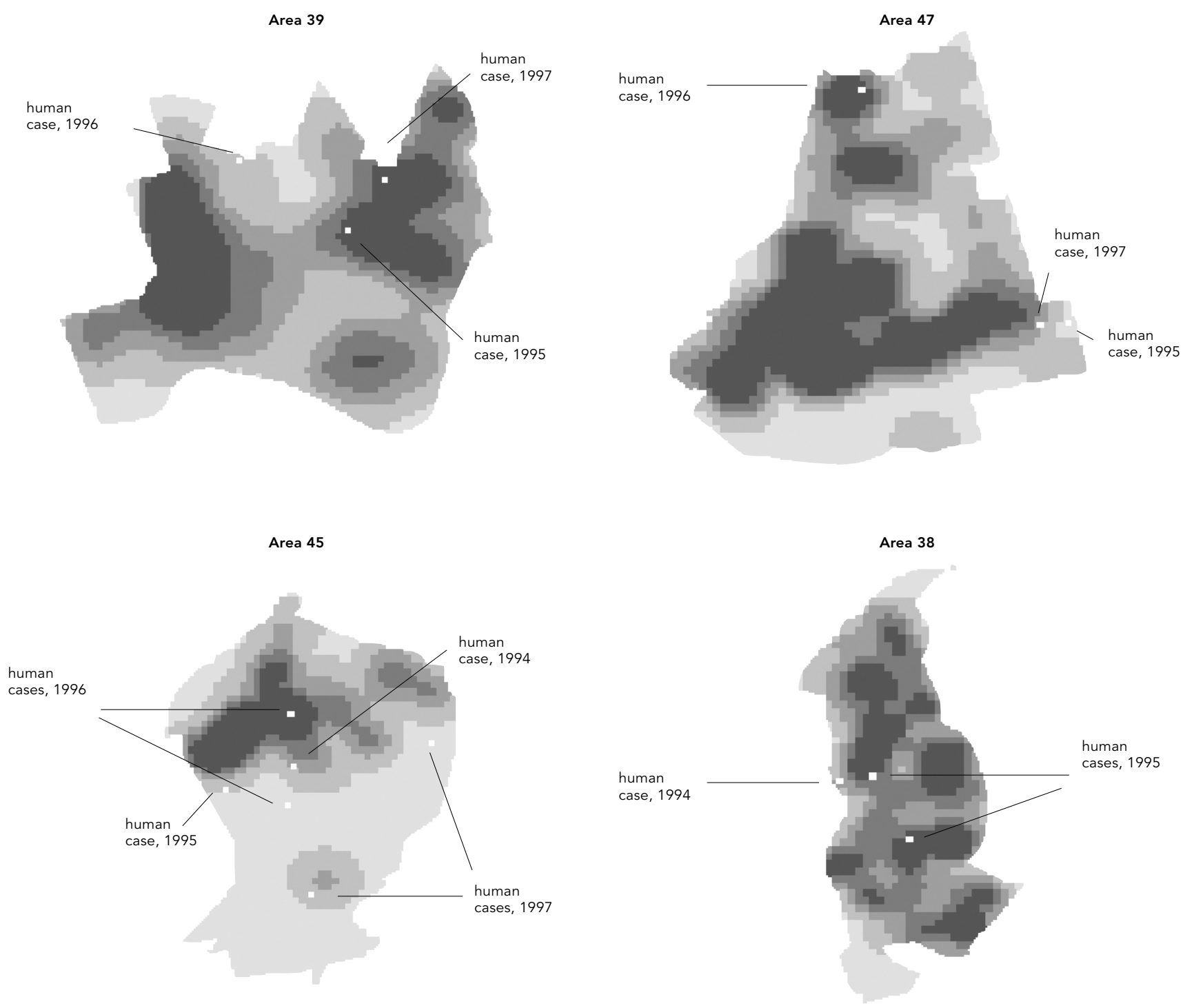

creased risk for other dogs and individuals living in the same neighborhood. This motivates health officials to propose seropositive dog control as one of the most important measures to control human VL (Alencar et al., 1991; Deane, 1956; Deane \& Deane, 1955, 1962; Deane et al., 1955; Magalhães et al., 1980).

In our study, we found strong evidence that human cases occur in areas where prevalence rates in dogs are high. This was observed at an ecological level through the regression analysis conducted across the AA's. The estimated lin- ear coefficient decrease through time and, although this decrease is not statistically significant, it suggests a decrease in the strength of the association between human and canine rates. The Bayesian Incidence Rate is approximately proportional to the dog's prevalence rate, since the estimated linear coefficient is close to one.

We believe that the control measures adopted in Belo Horizonte by ZS contributed to a lowering of the human incidence, and reducing the rates' association. In 1994, 3,402 
houses was sprayed with pyrethroids insecticides and this number increased to 46,980 in 1995. The next year, there were 46,258 sprayed houses and, in 1997, 22,640 houses. Additionally, in a large part of the city in 1996, the ZS used spatial spraying with organophosphate insecticide spray for Aedes aegypti because of a dengue epidemic and this action is likely to have reduced the $\mathrm{LV}$ vector population.

We concluded that there is space-time clustering of human cases. However, if we excluded pairs living in the same address, this spacetime clustering is less evident, as reflected by the $p$ value. The occurence of one human case in a household increases the chance of observing another human case in the same household in the next three months, but it does not change the chance of another event in its neighborhood. Therefore, the spatial-time interaction has a very short space span. In terms of public health measure, after one case is notified in a household, we suggest that it should be monitored for at least six months.

\section{Acknowledgments}

Project partially funded by the Pan-American Health Organization and the Academic Support Fund/Research Development Foundation, Universidade Federal de Minas Gerais, 1998. Grant no 12, Environment and Sustainable Development strategic program area.
Besides the ecological AA level correlation, we found also that within the AA's, there is an apparent correlation between canine prevalence and human incidence through kernel maps. Although we do not have statistical tests associated with these kernel maps, this suggestion comes from the location of human cases in regions of higher canine density.

This study has some limitations. We analyzed secondary data, not collected specifically for this study. Another limitation is the low number of cases for analysis. We believe that we included in our study most of the cases confirmed in Belo Horizonte during the period of study. Unfortunately, for some cases, it was not possible to geocode. We understand that our results contribute to support and assist public health decision-making processes in poor countries aimed at controlling the VL epidemic and its emergence in large cities such as Belo Horizonte.

\section{References}

ALENCAR, J. E.; NEVES, J. \& DIETZE, R., 1991. Leishmaniose visceral. In: Doenças Infecciosas e Parasitárias (R. Veronesi, org.), pp. 706-717, São Paulo: Editora Guanabara Koogan.

ASSUNÇÃO, R.; REIS, I. \& OLIVEIRA, C. L., in press Diffusion and prediction of Leishmaniasis in large Metropolitan area in Brazil with Bayesian space-time model. Statistic in Medicine.

DEANE, L. M., 1956. Leishmaniose Visceral no Brasil: Estudos sobre os Reservatórios e Transmissores Realizados no Estado do Ceará. Tese de Livre Docência, São Paulo: Faculdade de Medicina, Universidade Federal de São Paulo.

DEANE, L. M. \& DEANE, M. P., 1955. Observações preliminares sobre a importância comparativa do homem, do cão e da raposa (Lycalopex vetulus) como reservatório da Leishmania donovani em área endêmica de calazar no Ceará. O Hospital, 48:61-76.

DEANE, L. M. \& DEANE, M. P., 1962. Visceral leishmaniasis in Brazil: Geographical distribuition and transmission. Revista do Instituto de Medicina Tropical de São Paulo, 4:198-212. 
DEANE, L. M.; DEANE, M. P. \& ALENCAR, J. E., 1955. Observações sobre o combate ao Phlebotomus longipalpis pela dedetização domiciliária, em focos endêmicos de calazar no Ceará. Revista Brasileira de Malariologia e Doenças Tropicais, 7:131141.

FNS (Fundação Nacional de Saúde),1996. Controle, Diagnóstico e Tratamento da Leishmaniose Visceral. Brasília: Ministério da Saúde.

INFOMAP, 1995. Interactive Spatial Data Analysis, Infomap Version 6.1. London: Longman Scientific \& Technical.

KNOX, G., 1964. The detection of space-time interaction. Applied Statistics, 13:25-29.

MAGALHÃES, P. A.; MAYRINK, W.; COSTA, C. A.; MELO, M. N.; DIAS, M.; BATISTA, S. M.; MICHALICK, M. S. M. \& WILLIAMS, P., 1980. Calazar na zona do Vale do Rio Doce - Minas Gerais, Resultado das medidas profiláticas. Revista do Instituto de Medicina Tropical de São Paulo, 22:157-212.

MANTEL, N., 1967. The detection of disease clustering and a generalized regression approach. Cancer Research, 27:209-220.

MAPINFO CORPORATION, 1994. Map Info. New York: MapInfo Corporation.

MATHSOFT INCORPORATION, 1997. S-Plus for Windows, Version 4.0. Seattle: Mathsoft Inc.
MORSE, S. S., 1995. Factors in the emergence of infectious diseases. Emergeging Infectious Diseases, 1:7-15.

MOTT, K. E.; DESJEUX, P.; MONCAYO, A.; RANQUE, P. \& DE RAAP, P., 1991. Parasitoses et urbanization. Bulletin of the World Health Organization, 69:9-16.

OLIVEIRA, C. L., 1999. Epidemiologia da Leishmaniose Visceral em Belo Horizonte, 1994 a 1997. Dissertação de Mestrado, Belo Horizonte: Faculdade de Medicina, Universidade Federal de Minas Gerais.

RESENDE, C. L. \& BASTOS, O., 1959. Calazar infantil: Relato de um caso ocorrido em Belo Horizonte. Jornal de Pediatria, 24:324-331.

RIPLEY, B. D., 1977. Modelling spatial patterns. Journal of the Royal Statistical Society, 39:172-212.

SOUZA-SANTOS, R. \& CARVALHO, M. S., 2000. Análise da distribuição espacial de larvas de Aedes aegypti na Ilha do Governador, Rio de Janeiro, Brasil. Cadernos de Saúde Pública, 16:31-41.

STATA CORPORATION, 1999. Stata Statistical Software: Realease 6.0. College Station: Stata Corporation.

WIJEYARATNE, P. M.; ARSENAULT, J. \& MURPHY, C. J., 1994. Endemic disease and development the leishmaniasis. Acta Tropica, 56:265-382.

WHO (World Health Organization),1998. Leishmaniais Control. 28 November 1998 <http://www.who. $\mathrm{int} / \mathrm{ctd} / \mathrm{html} /$ homepage.html . 